\title{
Effects of working memory and attentional control training and their transfer onto fluid intelligence in early and late adulthood
}

\begin{abstract}
BACKGROUND
The interest in the possibility of improving cognitive functioning through training of basic cognitive processes is growing. This possibility is of particular importance for older adults, whose cognitive functions are weakened, and who may need cognitive rehabilitation. However, improvement of the performance in the tasks being trained is not the only goal of basic cognitive processes training. Far transfer, onto tasks different to the ones trained, and engaging other (usually complex) processes, including fluid intelligence, is an important goal of such training. Yet, meta-analyses suggest that results of studies on the far transfer phenomenon vary, and are not conclusive.
\end{abstract}

\section{PARTICIPANTS AND PROCEDURE}

One hundred and eighty healthy volunteers took part in this study. They were divided into groups: Experimental 1 (working memory training), Experimental 2 (attentional control training) and Control (non-contact). Each of these groups included participants from the two age subgroups: early and late adulthood. Training involved 7 appointments and lasted for about 4 weeks. Additional measurements, including an assessment of fluid intelligence, were performed on each group at baseline, and at the end of training.

\section{RESULTS}

Our results suggest that (a) the training of basic cognitive processes in adults leads to an improvement in the correctness, but not the speed, at which tasks are performed, (b) there is a transfer effect onto fluid intelligence, but this effect is weak, and (c) the effects of basic cognitive process training depend on the kind of trained tasks, age of participants and the interactions between these two factors: working memory training is equally as effective in both age groups, whereas training of attentional control is particularly effective among older individuals, and has limited efficacy for young adults.

\section{CONCLUSIONS}

Finally, one can conclude that the effectiveness of basic cognitive function training is limited. However, it can be significant, even in the aspect of transfer, under conditions related to the type of trained tasks and the age of the participants.

\section{KEY WORDS}

cognitive functioning; old age; rehabilitation; early intervention 


\section{BACKGROUND}

Psychology has long been interested in the possibility of improving cognitive functioning, as well as the effects of so-called cognitive interventions. This interest has been growing and there has been a significant increase in studies and publications on the topic in the past two decades. Meta-analyses of the published research reports have also emerged (e.g. Melby-Lervåg \& Hulme, 2013; Au et al., 2015; Karbach \& Verheaghen, 2014).

Researchers are particularly interested in proof of the efficacy of training basic cognitive functions (process-based training) (e.g. Jaeggi, Buschkuehl, Jonides, \& Perrig, 2008; Jaeggi, Buschkuehl, Jonides, \& Shah 2011; Jaušovec \& Jaušovec, 2012; von Bastian \& Oberauer, 2014; Schubert, Strobach, \& Karbach, 2014). This training should be differentiated from the more traditional strategy-based training (Stine-Morrow \& Basak, 2011; Karbach \& Verhaeghen, 2014; Schubert et al., 2014). In the case of process-based training, one neither teaches the participants particular strategies or rules, nor expands their system of knowledge. Instead, participants complete tasks requiring the use of strictly defined cognitive processes (Lustig, Shah, Seidler, \& Reuter-Lorenz, 2009). This is because process-based training is based on the assumption that cognitive functions can be improved through the repeated exercising of the underlying core mechanisms (Stine-Morrow \& Basak, 2011; Zając-Lamparska, Trempała, \& Mrówka, 2013).

This assumption leads one to expect transfer phenomena, including far transfer, i.e. improvement in performing tasks that are structurally different to the trained tasks and require engagement of different cognitive processes. The mechanism of transfer is, however, not explained by the transfer of trained skills and knowledge (procedures, representations, rules or heuristics) onto a new task situation ${ }^{1}$ (Barnett \& Ceci, 2002). Rather, it is explained through the so-called functional overlap of processes, i.e. engagement of the same basic cognitive processes in both task situations (Stine-Morrow \& Basak, 2011; Taatgen, 2013; Von Bastian, Langer, Jäncke, \& Oberauer, 2013; Jaeggi \& Buschkuehl, 2014; Jaeggi, Buschkuehl, Shah, \& Jonides, 2014; Schubert et al., 2014; Strenziok et al., 2014). Taking into account the aforementioned assumptions, the training of basic cognitive functions applies to core processes engaged in a broad spectrum of cognitive functions and exhibiting correlations with many other processes and functions, including more complex ones.

One of the important trends in research on the phenomenon of far transfer through training of basic cognitive processes and the mechanism of functional overlap of these processes is concerned with the possibility of improving fluid intelligence (Gf) (Jaeggi et al., 2008; Sternberg, 2008; Shipstead, Redick, \& Engle, 2012; Au et al., 2015). A clear dominance of studies using working memory (WM) training is visible in this trend, mainly using tasks in the n-back paradigm. Working memory, being a system that enables temporary storage and processing of information needed to perform cognitive tasks (Baddeley, 2002), generally fulfils the aforementioned criteria of a process with a wide range of correlations with other cognitive processes. Researchers have identified correlations between the capacity of WM and: attention, vocabulary acquisition, reading comprehension, problem-solving and intelligence (Feldman Barett, Tugade, \& Engle, 2004; Unsworth, Fukuda, Awh, \& Vogel, 2014). Meta-analyses estimate the degree of correlation between WM and G $f$ to be between .40 and .80 (Salthouse, 2014). Explanations of the nature of this relationship usually appeal to: (a) lower-order mechanisms as a source of the common variance of WM and Gf, e.g. capacity of WM (e.g. Süß, Oberauer, Wittman, Wilhelm, \& Schulze, 2002; Oberauer, Süß, Wilhelm, \& Sander, 2007; Fukuda, Vogel, Mayr, \& Awh, 2010), or speed of processing (mental speed) (e.g. Sheppard \& Vernon, 2008), (b) results of neuroimaging studies indicating that completion of tasks engaging WM and Gf activates similar areas of the brain, most of all the dorsolateral prefrontal cortex (DLPFC) and the parietal area (Miyake et al., 2000; Kane \& Engle, 2002; Gray, Chabris, \& Braver, 2003; Burgess, Gray, Conway, \& Braver, 2011).

Research on the possibility of improving Gf and, more generally, on the effect of training basic cognitive processes also uses tasks related to different components of the cognitive executive system, which is responsible for control over the course of action. Scientists use diverse terminology when discussing this system - they write about, inter alia: executive control, executive attention, attention control, and central executive component of the WM system (e.g. Engle, 2002; Kane \& Engle, 2002; Colom, Rubio, Shih, \& Santacreu, 2006; Unsworth, Spillers, Kane, Engle, \& Schmiedek, 2009; Karbach \& Verhaeghen, 2014; Schubert et al., 2014; Unsworth et al., 2014).

When talking about the central executive component of the WM system, it should be noted that WM and executive functions, including attentional control (AC), are also related to each other. Baddeley's multi-component model of WM (Baddeley, 1986, 2002) assumes the existence of a central executive system that, through attention processes, holds control over information processing and coordinates the action of memory buffers (cf. Nęcka, Orzechowski, \& Szymura, 2006; Jodzio, 2008). Other authors (e.g. Engle \& Kane, 2004; Unsworth et al., 2014) also highlight that attention control is an important component of WM, using it to explain both individual differences in WM capacity and the relationship between WM and higher-order cognitive processes, including $\mathrm{G} f^{2}$. Attention control was supposed to play a mediating role in this approach (Engle \& Kane, 2004); however, studies have 
shown that it explains only part of the shared variance of WM and Gf(Unsworth et al., 2009; Unsworth \& Spillers, 2010; Unsworth et al., 2014).

Independent of the nature of this relationship, results of research on far transfer in training of basic cognitive processes, including the possibility of improvement of Gf, are heterogeneous and inconclusive. Jaeggi and her team obtained some promising results (2008) showing that WM training using the n-back task leads to an improvement in performance of tasks measuring $\mathrm{G} f$. However, such an effect was not observed in many subsequent attempts to replicate it (Chooi \& Thompson, 2012; Colom et al., 2013; Redick et al., 2013; Thompson et al., 2013). Recent meta-analyses on published research reports are not conclusive either. A meta-analysis of 20 studies using training based on the n-back task with adults (aged 18-50) showed a small, but positive, influence of this type of training on measures of $\mathrm{G} f$ (Au et al., 2015). Also, a review of 23 studies regarding the effects of WM training performed according to varying programmes on groups of children, adults and clinical groups suggested that a close transfer occurs, but did not support the presence of far transfer (Melby-Lervåg \& Hume, 2013).

Moreover, the role of age of the participants in the effectiveness of training of basic cognitive processes is unclear. Many researchers have pointed to the importance of this variable (e.g. Borella, Carretti, Riboldi, \& De Beni, 2010; Zinke et al., 2014). The problem of effectiveness of cognitive interventions among individuals in their late adulthood appears to be particularly interesting and important. Its practical importance is obvious in the light of current demographic changes - average lifespan becoming longer and the ageing of populations (Kroemeke \& Gruszczyńska, 2014; Leszko, Zając-Lamparska, \& Trempała, 2015) - especially because weakening of many cognitive processes is associated with ageing. This includes WM, executive and attentional functions and $\mathrm{G} f$ (e.g. Salthouse, 1994; Dennis \& Cabeza, 2008; Hofer $\&$ Alwin, 2008). These decreases in functioning have an important place among the numerous losses experienced when ageing, which can significantly influence the perceived quality of life of older adults (Gamrowska \& Steuden, 2014). In this context, the value of conducting successful cognitive rehabilitation with older adults cannot be emphasized enough.

Results of research using strategy-based training have usually shown larger effects among young people than among older adults. This was explained to be the result of a reduction of developmental reserves and the decrease of plasticity associated with ageing (Baltes, 1997; Brehmer, Li, Müller, von Oertzen, \& Lindenberger, 2007; Hertzog, Kramer, Wilson, \& Lindenberger, 2009; Stine-Morrow \& Basak, 2011; Karbach \& Verhaeghen, 2014). Larger benefits for young people than older adults were also observed for some process-based training methods which train WM (Brehmer, Westerberg, \& Bäckman, 2012; Dahlin, Nyberg, Bäckman, \& Neely, 2008; Dorbath, Hasselhorn, \& Titz, 2011; Schmiedek, Bauer, Lövdén, Brose, \& Lindenberger, 2010; Zinke et al., 2014). These results were sometimes interpreted in the context of the so-called Matthew effect (or accumulated advantage) - that is, a larger increase in skills among people who already have an advantage in these very skills (in this case among young adults, for whom we do not observe the cognitive decline that is present among older adults) (von Bastian \& Oberauer, 2014). However, there are also studies in which WM training was shown to be more effective in late adulthood (Li et al., 2008; von Bastian et al., 2013). Likewise, some studies using executive function training have shown larger benefits from the training among older adults than young adults (e.g. Bherer et al., 2008; Karbach \& Kray, 2009). In this case, the greater effectiveness of basic cognitive function training in late, rather than early, adulthood can be explained through the so-called compensatory effect of training (von Bastian \& Oberauer, 2014). This is the idea that the cognitive processes stimulated in the course of training are at their peak level in the case of young individuals, whereas among older adults they usually show the aforementioned blunting, which makes room for the improvement of these processes induced by training (Karbach \& Verhaeghen, 2014) ${ }^{3}$.

\section{GOAL OF THE CURRENT STUDY}

The main goal of this research was to assess the scope of influence of training basic cognitive processes (process-based training) on the cognitive functioning of adult individuals. The assessment of effects of training considered two aspects: improvement of performance in trained tasks, and transfer to tasks measuring $\mathrm{G} f$. At the same time, as part of the study, we compared the effects of training using two different types of tasks: one engaging the process of refreshing information in WM (n-back tasks), and the other engaging processes of AC (Donders' tasks - requiring simple reactions, complex discriminatory reactions and complex choice reactions). Moreover, the study aimed to determine the relationship between the effects of training and age, which is why the potentially moderating influence of age group (early and late adulthood) was taken into account.

The following research questions were formed:

1. Does the training of basic cognitive functions lead to an improvement of performance in the trained tasks and an increase in $\mathrm{G} f$ ?

2. Do the effects of training depend on the type of tasks being trained (training of WM vs. training of $\mathrm{AC}$ )?

3. Do the effects of training depend on the age of the participants (individuals in their early adulthood vs. late adulthood)?
Effects of training of basic cognitive functions in adult individuals 

Ludmiła
Zając-Lamparska, Janusz Trempała

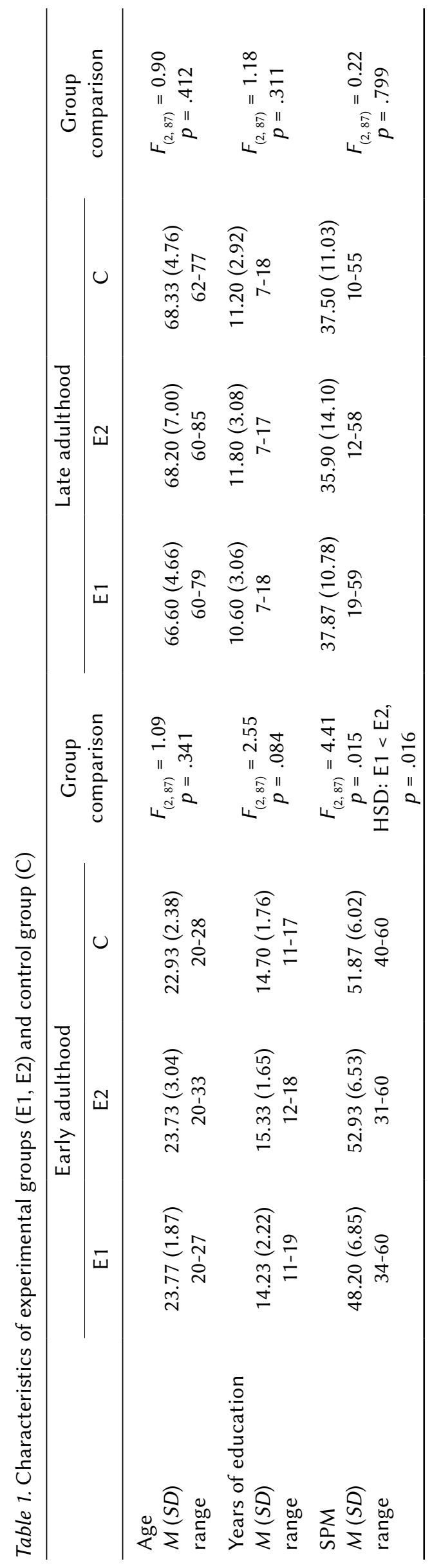

\section{PARTICIPANTS AND PROCEDURE}

SAMPLE

One hundred and eighty healthy volunteers took part in the study. They were selected by snowball sampling. Participants were divided into three groups: Experimental 1 (E1, where training based on tasks engaging WM was employed, $n=60$ ), Experimental 2 (E2, where training based on tasks engaging $\mathrm{AC}$ were employed, $n=60)$ and Control (C, the so-called waiting group, $n=60)$. Each of these groups included participants from the two age subgroups: early adulthood $(n=30)$ and late adulthood $(n=30)$. Moreover, all subgroups were balanced in terms of gender. The characteristics of the experimental groups and the control group, including age, education and raw scores for the Raven's Standard Progressive Matrices Test (SPM), at baseline are presented in Table 1.

The following were exclusion criteria: (a) symptoms of dementia, (b) somatic or psychiatric illnesses influencing cognitive function, (c) the need to take medications that influence cognitive functions, (d) insufficient motor ability to use a computer, (e) uncorrected sight and/or hearing problems. Information needed to use the exclusion criteria was gathered in a structured interview.

\section{MEASUREMENT}

Working memory. An application named NBackTaskSessions was used for the WM training, as well as its baseline and final assessments. It was written using the Microsoft .NET Framework, version 4.0. Tasks completed via this application were based on the n-back paradigm and they were 1-back and 2-back single n-back tasks. The essence of $n$-back tasks is to react to stimuli identical to those presented "n" items back. NBackTaskSessions used letters (printed) from the Polish alphabet (excluding Polish diacritic marks) as stimuli. They were shown on the screen of a portable computer. The participants were instructed to press a certain button every time the current stimulus was identical to the previous stimulus (1-back), or to the letter shown two stimuli ago (2-back). In each session $20+$ " $n$ " stimuli were presented (depending on the value of "n-back"), including 6 goals (the stimuli that a participant should react to) and $14+$ " $n$ " distractors. Each single stimulus was presented for $500 \mathrm{~ms}$, and the time interval between the presentation of stimuli was $2500 \mathrm{~ms}$ (the total time of one trial being $3000 \mathrm{~ms}$ ). In order to assess WM at the baseline and at the end, the following indices were used: (a) the correctness parameter: the sum of correct answers (that is, reactions to correct letters and inhibition of reaction to incorrect letters) in the 2-back task; (b) the speed parameter: mean time of correct reactions (reactions to correct letters) in milliseconds in the 2-back task. 
Attentional control. An application named FundamentalRecogFunctions was used for the attention control training, as well as its baseline and final assessments. As before, it was written using the Microsoft .NET Framework, version 4.0. In line with Donders' proposal (Nęcka et al., 2006), tasks completed via the application required three types of reactions: (1) simple reactions - where one needs to react to a single stimulus (goal), given in the instructions, by pressing the button indicated in the instructions, where apart from that stimulus, no other stimuli are presented (the one stimulus is presented at varying time intervals); (2) complex discriminatory reactions - where one needs to react to a single stimulus (goal), given in the instructions, by pressing the correct (as per instructions) button, where, alongside that stimulus, other stimuli are presented, and one needs to inhibit their reaction (the "go/no-go" principle); (3) complex reactions with choice - where one is instructed to react to two stimuli in a correct way - that is, by pressing the correct buttons (as per instruction), where alongside that stimulus, other stimuli are presented and one needs to inhibit their reaction. Geometric figures of different colours and letters from the Polish alphabet (excluding Polish diacritic marks) were used, and each task consisted of either only letters or only figures. In the case of simple reaction tasks, 10 goal stimuli were shown in a single session. Each of them was presented for $500 \mathrm{~ms}$. The total time of this type of task was $15000 \mathrm{~ms}$, during which time goal stimuli were presented at varying time intervals, chosen randomly before programming the tasks. In the case of tasks requiring complex reactions (discriminatory or with choice), 30 stimuli were presented during a single task - including 10 goal stimuli and 20 distractor stimuli. Each stimulus was presented for $500 \mathrm{~ms}$, and the time interval between the presentation of stimuli was $2500 \mathrm{~ms}$. The following indices were used to assess AC at baseline and at the end: (a) the correctness parameter: the sum of incorrect answers (for all types of reactions: no reaction to goal stimulus, no inhibition of reaction to a distractor stimulus; and additionally, in the case of complex choice reactions, incorrect choice of button); (b) the speed parameter: the mean time of correct reactions (reactions to goal stimuli) in milliseconds.
Fluid intelligence. The Polish adaptation of Raven's Standard Progressive Matrices Test (Polish: Test matryc Ravena $w$ wersji standard - forma klasyczna [TMS-K]) was used to measure G $f$ at baseline and at the end (Jaworowska \& Szustrowa, 2007). The participants had no time limit to complete Raven's test. Raw scores were used to assess $\mathrm{G} f$.

\section{STUDY FLOWCHART}

The experimental plan of the study included two experimental groups and one control group, as well as measurements at baseline and at the end in each of the groups (cf. Brzeziński, 2000; see Figure 1). The experimental factor was a computerised training of basic cognitive processes, different for the two experimental groups (WM training vs. AC training), and done using computer software designed for the purposes of the study. The training was divided into 7 sessions and took about 4 weeks to complete. Training sessions took place at participants' homes, with trained instructors and using portable computers (brought by the instructors). In line with the requirements of the software used in the study, the computers had the following parameters: a processor compatible with $86 \times$ architecture and a graphics card supporting $1600 \times 1900$ resolution (or higher) with a 32-bit colour depth. All of the task instructions were given within the software, so the role of the instructors was limited to giving introductory instructions regarding the use of the software and addressing any concerns the participants might have. No contact was made with participants from the control group during the training period. In all of the groups, measurements were made at baseline and at the end, where performance in the trained task and $\mathrm{G} f$ were assessed.

\section{RESULTS}

\section{EFFECTS OF TRAINING: CHANGE IN PERFORMANCE OF THE TRAINED TASKS}

Working memory training. Pre-test-post-test variance analysis with two qualitative predictors (belonging
Effects of training of basic cognitive functions in adult individuals

\begin{tabular}{|c|c|c|c|}
\hline Group & pre-test & 4 weeks & post-test \\
\hline $\begin{array}{l}\text { E1 } \\
\text { ( } 2 \text { age groups) } \\
n=60\end{array}$ & \multirow{3}{*}{$\begin{array}{l}\text { Measurements: } \\
\text { Working Memory } \\
\text { Attentional Control } \\
\text { Fluid Intelligence }\end{array}$} & $\begin{array}{l}\text { TRAINING: } \\
\text { Working Memory } \\
\text { (7 sessions }) \\
\end{array}$ & \multirow{3}{*}{$\begin{array}{l}\text { Measurements: } \\
\text { Working memory } \\
\text { Attentional control } \\
\text { Fluid intelligence }\end{array}$} \\
\hline $\begin{array}{l}\text { E2 } \\
\text { ( } 2 \text { age groups) } \\
n=60\end{array}$ & & $\begin{array}{c}\text { TRAINING: } \\
\text { Attentional Control } \\
\text { (7 sessions) }\end{array}$ & \\
\hline $\begin{array}{l}C \\
(2 \text { age groups) } \\
n=60\end{array}$ & & No intervention & \\
\hline
\end{tabular}

Figure 1. Study flowchart. 

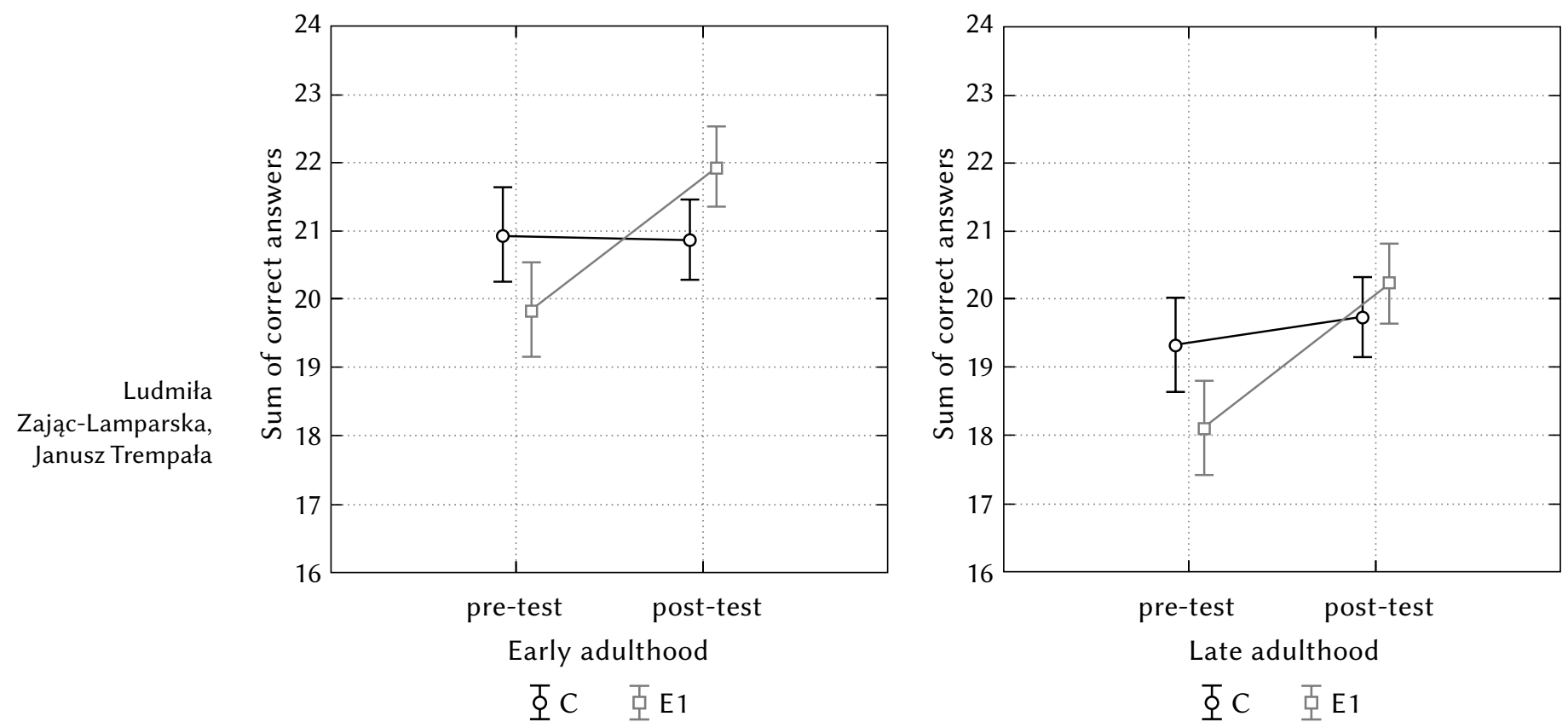

Figure 2. Comparison of changes in the correctness of performance of the 2-back task for experimental (E1) and control (C) groups, taking into account early adulthood and late adulthood age subgroups.

to group E1 vs. K, and belonging to age group early vs. late adulthood). Performance at the 2-back task was shown to be significantly higher at the end measurement than at baseline: $F(1,116)=60.23, p<.001$, $\eta^{2} p=.340$. The increase was bigger in the experimental group (E1), members of which did the WM training, than in the control group $[F(1,116)=43.93, p<.001$, $\left.\eta^{2} p=.270\right]$ and independent of the age of the participants $\left[F(1,116)=0.54, p=.463, \eta^{2} p=.004\right]$ (Figure 2). In terms of speed, the second reaction time was

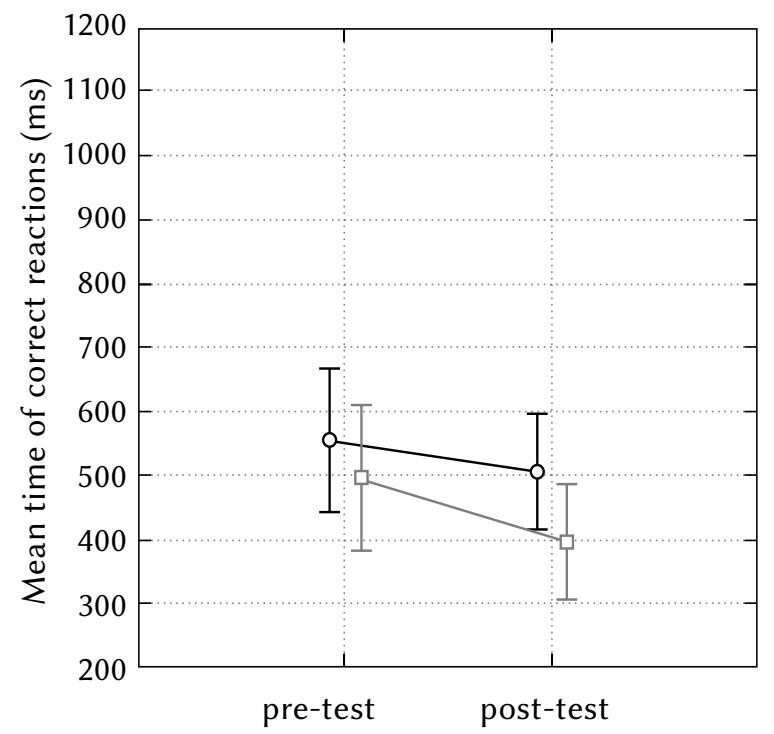

Early adulthood

$$
\text { 오 C 모 } \mathrm{E} 1
$$

shorter than the first, although this effect was small: $F(1,116)=4.74, p=.031, \eta^{2} p=.040$. Moreover, participation in the WM training did not play a role here $\left[F(1,116)=1.38, p=.242, \eta^{2} p=.010\right]$, and was independent of the age group $[F(1,116)=0.07, p=.788$, $\left.\eta^{2} p=.001\right]$ (Figure 3). For correctness, which increased significantly due to training, contrast analysis was also performed, in which pre-test and post-test scores were compared separately for the experimental group (E1) and the control group, subdivided by

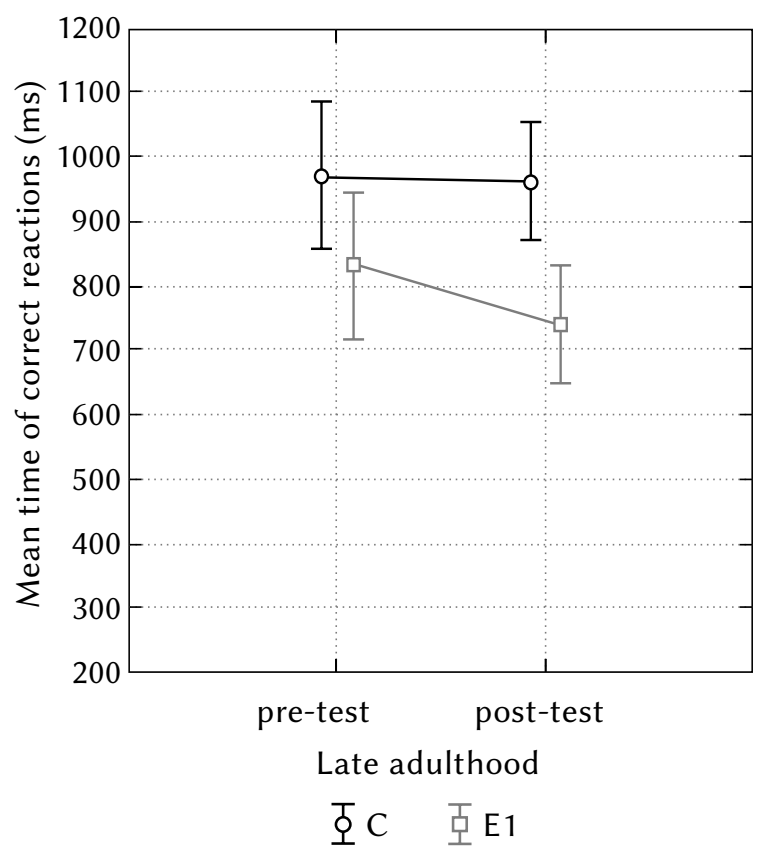

Figure 3. Comparison of changes in speed of 2-back task performance in the experimental (E1) and control (C) groups, taking into account early adulthood and late adulthood age subgroups. 
age. Based on the results of this analysis, one can conclude that there was a significant increase in the correctness parameter in the experimental group, in both age subgroups (early adulthood: $F(1,116)=50.95$, $p<.001$, late adulthood: $F(1,116)=52.58, p<.001)$, but not in the control group (early adulthood: $F(1,116)=0.05, p=.821$, late adulthood: $F(1,116)=1.85$, $p=.177)$.

Attentional control training. Analysis of variance was conducted in the same way as it was done for WM training. The results suggest that the baseline and end measurements differ in terms of the number of mistakes in tasks engaging $\mathrm{AC}: F(1,116)=18.60$, $p<.001, \eta^{2} p=.140$. However, this effect is different for the experimental (E2) and control (C) group: $F(1,116)=21.14, p<.001, \eta^{2} p=.150$. Moreover, the difference between the experimental and control groups was not only more pronounced among the participants in late adulthood, in comparison to those in their early adulthood, but also had a different character: $F(1,116)=6.35, p=.013, \eta^{2} p=.050$. For the older participants in the experimental group, the number of errors in the second measurement decreased, whereas in the control group it increased. Among the younger adults in both the experimental and control groups there was a decrease in the number of errors in the second measurement, with the experimental group seeing a bigger decrease (Figure 4). There were no significant differences in the speed of AC task completion: $F(1,116)=0.60, p=.438, \eta^{2} p=.005$. This was independent of participation in AC training: $F(1,116)=3.36$, $p=.069, \eta^{2} p=.030$. This effect was not modified by the participants' age group: $F(1,116)=1.97$,

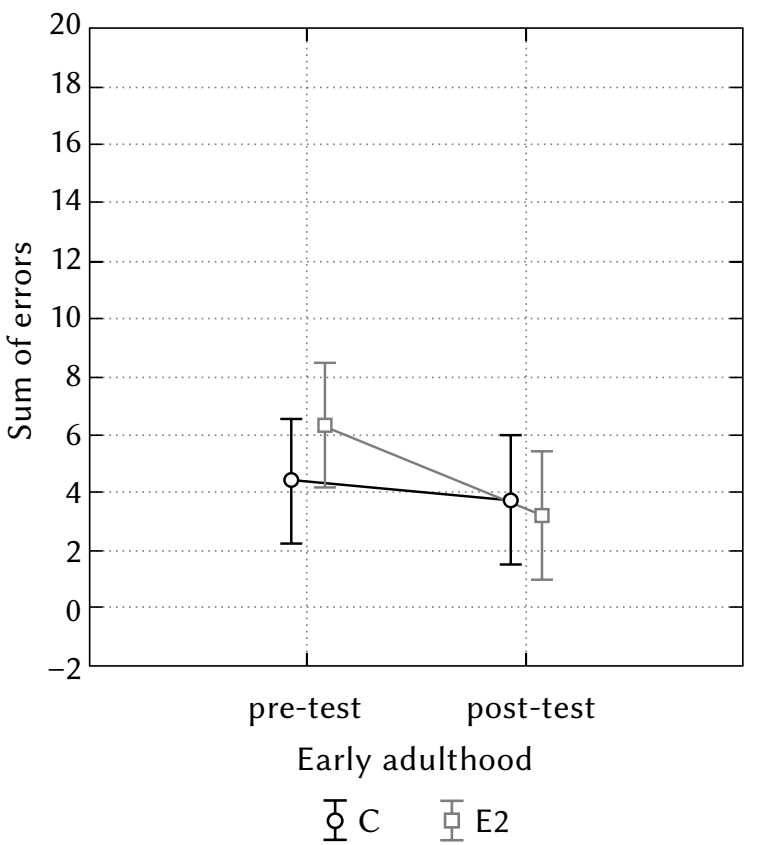

$p=.163, \eta^{2} p=.020$ (Figure 5). For correctness, which was shown to increase (as the errors decreased) due to AC training, an additional contrast analysis was performed: we compared the results at baseline and at the end measurement for the experimental group (E2) and the control (divided into age subgroups). This analysis revealed a significant increase in correctness in the experimental group, primarily among older participants $[F(1,116)=39.23, p<.001]$, but also among younger adults $[F(1,116)=7.01$, $p=.009]$. There were no significant changes in either age subgroup of the control group (early adulthood: $F(1,116)=0.32, p=.570$; late adulthood: $F(1,116)=0.73$, $p=.395)$.

\section{EFFECTS OF TRAINING: TRANSFER ONTO FLUID INTELLIGENCE}

Pre-test-post-test analysis of variance with two qualitative predictors was used (belonging to group: $\mathrm{E} 1 / \mathrm{E} 2 / \mathrm{K}$ and belonging to age group: early adulthood vs. late adulthood). It showed three significant effects regarding changes in $\mathrm{G} f$ due to training/repeated measurement. The first effect concerned differences in intelligence levels between baseline and end measurements. The results of Raven's test were higher at the end in comparison to the baseline: $F(1,174)=44.00, p<.001, \eta^{2} p=.200$. Moreover, the size of the improvement was dependent on the group $(\mathrm{E} 1 / \mathrm{E} 2 / \mathrm{K})$ and it was larger for the experimental groups than for the control group $F(1,174)=5.33$, $p=.005, \eta^{2} p=.060$. Furthermore, this effect was mod-

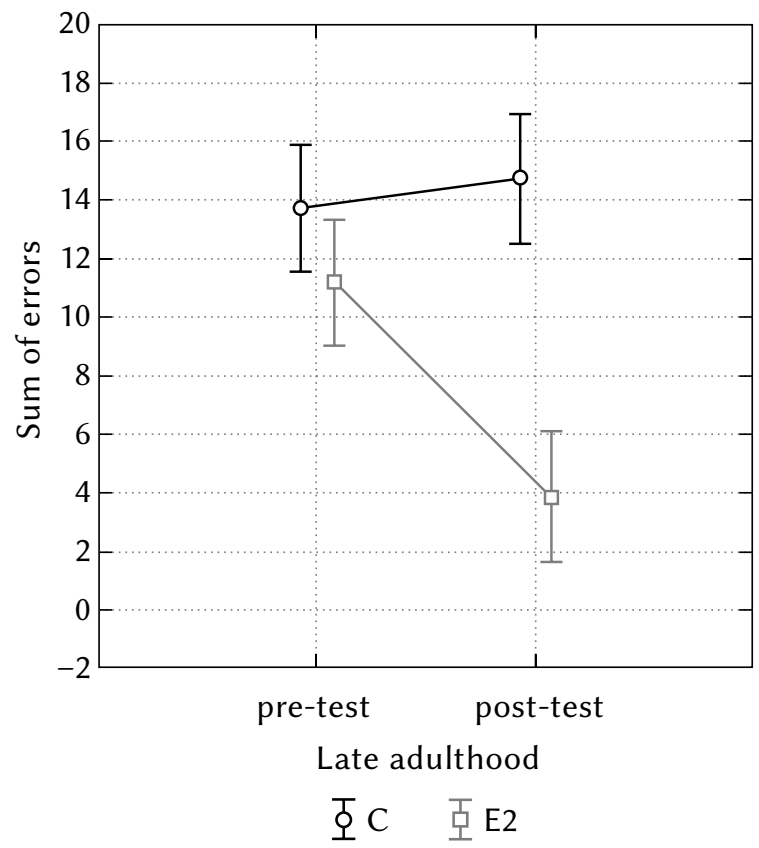

Effects of training of basic cognitive functions in adult individuals

Figure 4. Comparison of changes in the correctness (number of errors) in performance of tasks requiring simple reactions, complex discriminatory reactions, and complex choice reactions in experimental (E2) and control (C) groups, taking into account early adulthood and late adulthood age subgroups. 
Ludmiła

Zając-Lamparska, Janusz Trempała

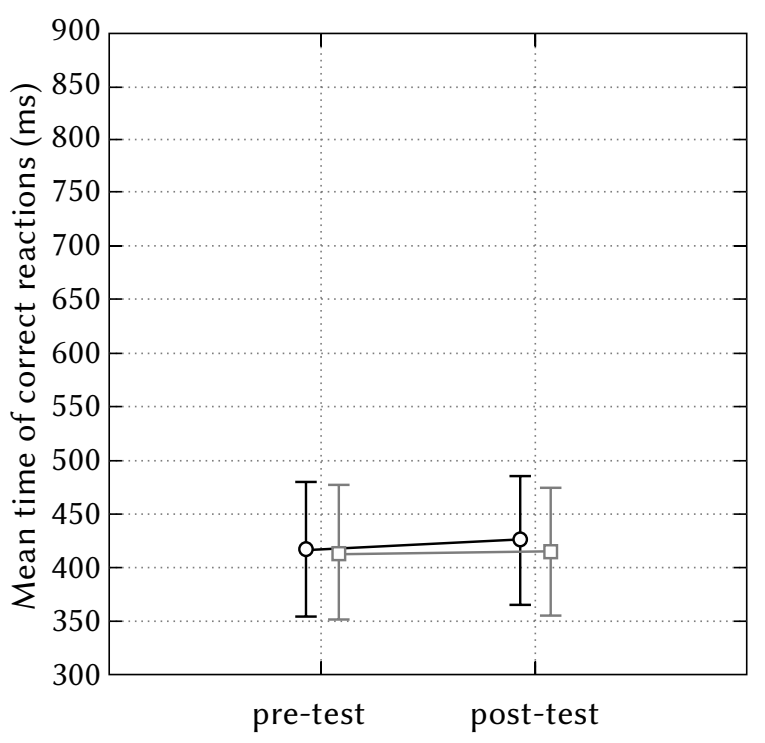

Early adulthood

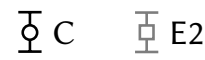

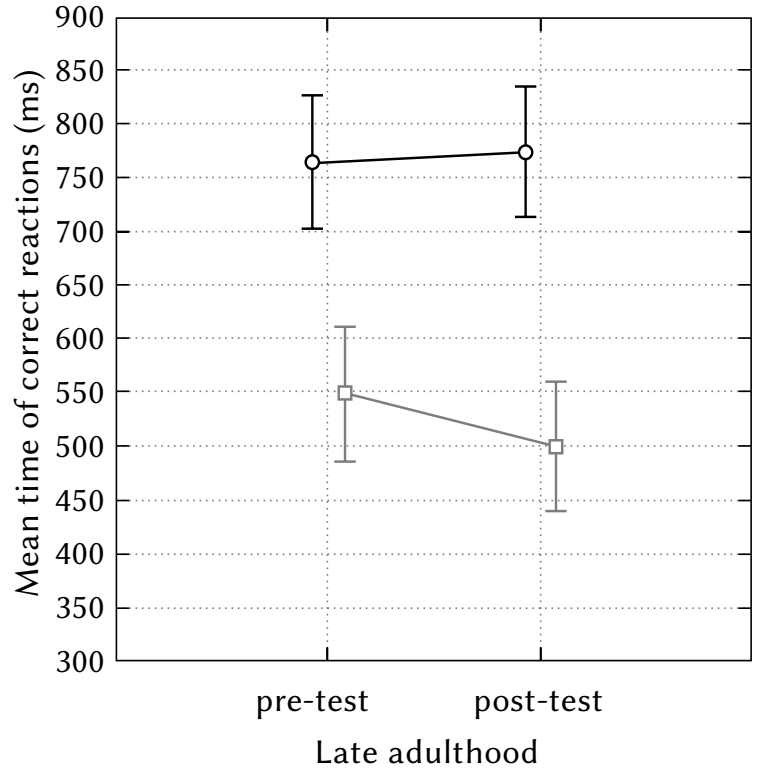

오 C 돌

Figure 5. Comparison of changes in speed of performance of tasks requiring simple reactions, complex discriminatory reactions, and complex choice reactions in experimental (E2) and control (C) groups, taking into account early adulthood and late adulthood age subgroups.
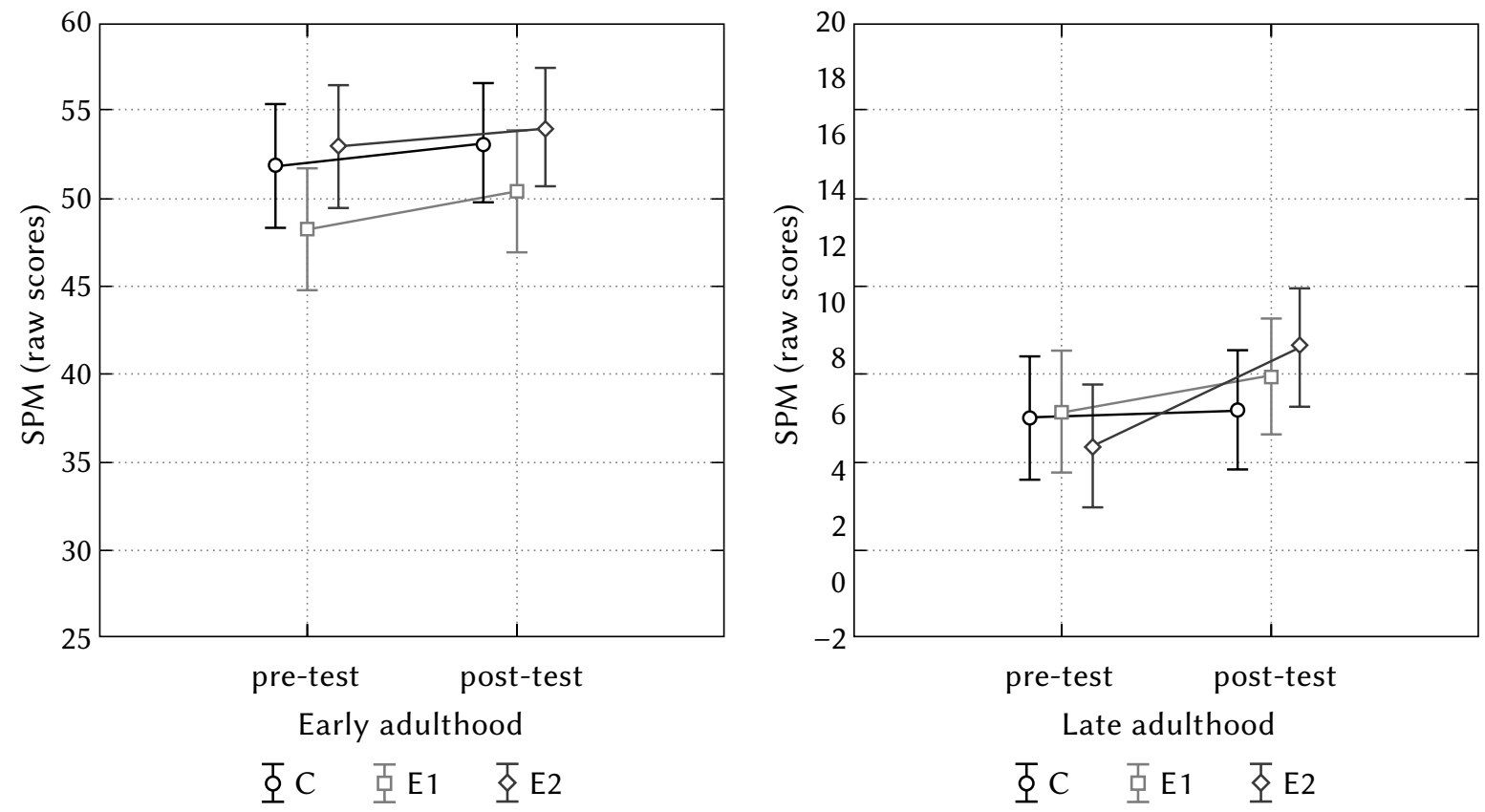

Figure 6. Comparison of changes in raw scores for Raven's test, which are a measure of fluid intelligence, in the experimental working memory training group (E1), experimental attentional control training group (E2) and the control group (C), taking into account early adulthood and late adulthood age subgroups.

ified by the age of the participants $[F(1,174)=7.19$, $\left.p=.001, \eta^{2} p=.080\right]$, as with the WM training group the improvement was similar in both age subgroups, whereas in the AC training group there was an unambiguously larger improvement among the older participants than among the younger ones (Figure 6). These results were complemented by contrast anal- ysis regarding measurements at the baseline and at the end in the experimental groups (E1 and E2 separately) and the control group, taking into account the age subgroups. It suggests that a significant improvement of Raven's test scores took place:

- In the experimental group which completed the WM training, in both age subgroups (early adult- 
hood: $F(1,174)=7.41, p=.007$, late adulthood: $F(1,174)=6.72, p=.010)$;

- In the experimental group which completed the AC training, only among the older participants: $F(1,174)=53.96, p<.001$, but not among individuals in early adulthood: $F(1,174)=1.91, p=.168$.

In the control group there were no significant changes in the results of Raven's test, used as a measure of $\mathrm{G} f$, independently of the age of participants (early adulthood: $F(1,174)=2.56, p=.112$, late adulthood: $F(1,174)=0.37, p=.546)$.

\section{DISCUSSION}

The main goal of the current study was to assess the scope of impact of training basic cognitive processes (the refreshing of information in the WM and AC) on task performance (n-back and Donders' tasks respectively) and the transfer of these training effects onto Raven's test tasks (TMS-K), which measure Gf, taking into account the age of participants (early adulthood vs. late adulthood).

From the point of view of the research questions, the presented results lead to three important conclusions.

First, a relatively small amount of training of WM and AC in adulthood leads to an increase of correctness in completion of the trained tasks, but it does not significantly increase the speed of completion of these tasks.

Second, such training leads to an improvement in performance at tasks measuring $\mathrm{G} f$, but this effect is rather weak.

Third, the scope of the effects of basic cognitive training depends on the type of trained tasks, the age of the participants, as well as interactions between these two factors. Namely:

a) in terms of improvement of trained task performance: WM training is as effective in both age groups, whereas AC training is more effective in the older age group;

b) in terms of transfer to $\mathrm{G} f$ : training of WM is equally effective in both age groups, whereas AC training is effective only in the older age group, where it was also more effective than the WM training.

Overall, based on the results of the study, one can conclude that the possibility of improving cognitive functioning through short periods of training of basic cognitive functions is limited. Such training results in an improvement of the performance in the trained tasks, but the far transfer onto $\mathrm{G} f$ is small. This remains in agreement with the aforementioned meta-analyses, which confirm the effect of improvement of the performance of the trained tasks, as well as the existence of close transfer (onto similar tasks), but no far transfer to overall cognitive ability (Melby-Lervåg \& Hulme, 2013), or suggest a weak far transfer effect - a small positive influence of training on $\mathrm{G} f(\mathrm{Au}$ et al., 2015). Such results support the need for further research on changes in mental and brain processes that take place during cognitive training. Further research may extend our knowledge about the 'overlap' of the same basic executive processes (and the corresponding networks) in structurally different tasks, as is often assumed by other studies concerned with that problem (see e.g. Garon, Bryson, \& Smith, 2008; Von Bastian, Langer, Jäncke, \& Oberauer, 2013; Jaeggi \& Buschkuehl, 2014; Jaeggi et al., 2014; Schubert et al., 2014; Strenziok et al., 2014).

The presented results provide additional data which require separate discussion. It seems that they may be of importance for future research on the matter.

First, our results have shown that as a result of the basic cognitive function training used in this study (that is, WM and AC) the correctness of answers increased, without an increase in the speed of response. This could have been caused by the way that subjects were instructed. The instructions given to the subjects via the computer software were about how to correctly solve a task, and did not contain an instruction to work as fast as possible. This might have led the participants to focus their attention on accuracy when performing the tasks, at the cost of reacting quickly.

Secondly, the results revealed that age plays a role in the effectiveness of basic cognitive function training. We observed two patterns related to age.

a) Older individuals show a training-induced improvement of performance in the trained tasks that is not smaller than that shown by young adults. At the end of training, the scores of older individuals are still usually worse than those of the younger group (though in the case of AC training the post-test correctness indices are similar in both age groups), but the gradient of skills in the older age group is comparable to the younger group in the case of the WM training, and even larger in the case of AC training. Therefore, these results suggest that, in the process of aging, while there is a decrease in cognitive ability, the plasticity potential and developmental reserves remain preserved (cf. Baltes, 1997; Brehmer et al., 2007; Hertzog et al., 2009).

b) AC training turned out to be particularly effective in the older adult group (in terms of both performance in the trained tasks and transfer), while being of limited effectiveness in the younger age group, where $\mathrm{G} f$ did not improve as a result of this training. This result can be interpreted in terms of the previously mentioned compensatory effect of training (von Bastian \& Oberauer, 2014). In line with this interpretation, if AC is particularly weakened among older individuals, then as a consequence there is a large potential for improvement as a result of training ${ }^{4}$. In the case of individuals in their early adulthood, whose AC functions at opti-
Effects of training of basic cognitive functions in adult individuals 
mal levels, there is no such potential for improvement. Because the mechanism of far-transfer in basic cognitive processes is based on the improvement of core processes used in more complex cognitive functions (onto which, as an effect, a transfer occurs), one can suppose that the large improvement in AC among older individuals also leads to the improvement of their G $f$. In turn, the much smaller change observed among young individuals, for whom AC is already optimal before training, Ludmiła Zając-Lamparska, Janusz Trempała

\section{CONCLUSIONS}

Finally, one can conclude that the effectiveness of basic cognitive function training is limited. However, it can be significant, even in the aspect of transfer, under the following conditions: (a) the type of training tasks (types of trained cognitive processes), and (b) the target group being trained. If cognitive processes that are weakened (in the given group) are trained, and these are at the same time core elements of other, more complex processes and functions, it should be possible to obtain both effects - improvement of task performance, and transfer. This mechanism seems particularly promising in the case of individuals in late adulthood, not only because the process of aging is associated with a decrease of many basic cognitive functions, but also because this decrease is used to explain the overall lower level of cognitive functioning of older individuals (Hasher \& Zacks, 1988; Verhaeghen, Cerella, Bopp, \& Basak, 2006; Dennis \& Cabeza, 2008). So, in this situation, it is very probable that the training will have a compensatory effect.

Therefore, despite the fact that the hereby presented study is basic research, the results are also of practical importance. Training of basic cognitive functions can be used in rehabilitation programmes for older adults, and - in line with the current results - their effectiveness will be ensured by directing them at these basic cognitive processes, which are particularly weakened in the process of ageing. The identification of such processes can be based not only on the knowledge about cognitive ageing in general, but also on a diagnosis of the cognitive functioning of a given individual, at whom the given rehabilitation programme is aimed. This type of tailoring of cognitive interventions may also increase their efficacy.

There is quite a large need for cognitive interventions for older adults in our ageing society. Even in the case of a non-pathological ageing process, there is some level of weakening of cognitive functions, and cognitive ability is an important element of an individual's mental health. It is important not only for the quality of an individual's independence and their functioning in society, but also for their subjectively perceived quality of life.

\section{ACKNOWLEDGMENTS}

We would like to thank Michał Kostrzewski for programming the applications for the training conducted as part of this research project. We would like to thank Joanna Janicka, Monika Wronka and Mateusz Zań for conducting the training sessions and collecting the data.

\section{ENDNOTES}

1 This obviously does not exclude additional positive effects resulting from e.g. acquiring certain strategies or automatisation of certain cognitive functions due to training (von Bastian \& Oberau$\mathrm{er}, 2014)$. However, in the case of training of basic cognitive functions, such effects are not intentionally realised.

2 Beliefs on that subject have evolved, from concentrating on AC only (Engle \& Kane, 2004), through the dual-component model of WM, according to which, for shared variance of WM and G $f$, both $\mathrm{AC}$ and the ability to search for and extract information from long-term memory play a mediating role (Unsworth \& Engle, 2007; Unsworth et al., 2009; Unsworth \& Spillers, 2010); towards the multifaceted model of WM, which assumes the existence of many factors mediating the WM-G $f$ relation. These include AC, long-term memory, and WM capacity (Unsworth et al., 2014).

3 This explanation corresponds to research results in which subjects with low baseline trained task performance (independent of age) showed a greater improvement and greater effect of transfer due to training (Karbach \& Kray, 2009).

4 The WM obviously also shows a decrease during ageing, but in this experiment, the age-related differences at baseline were larger in the case of tasks engaging AC.

\section{References}

Au, J., Sheehan, E., Tsai, N., Duncan, G. J., Buschkuehl, M., \& Jaeggi, S. M. (2015). Improving fluid intelligence with training on working memory: a meta-analysis. Psychonomic Bulletin \& Review, 22, 366-377. doi: 10.3758/s13423-014-0699-x

Baddeley, A. D. (1986). Working memory. Oxford, UK: Claredon Press.

Baddeley, A. D. (2002). Is working memory still working? European Psychologist, 7, 85-97.

Baltes, P. B. (1997). On the incomplete architecture of human ontogeny: selection, optimization, and compensation as foundation of developmental theory. American Psychologist, 52, 366-380.

Barnett, S. M., \& Ceci, S. J. (2002). When and where do we apply what we learn? A taxonomy for far 
transfer. Psychological Bulletin, 128, 612-637. doi: 10.1037/0033-2909.128.4.612

Bherer, L., Kramer, A. F., Peterson, M. S., Colcombe, S., Erickson, K., \& Becic, E. (2008). Transfer effects in task-set cost and dual-task cost after dual-task training in older and younger adults: further evidence for cognitive plasticity in attentional control in late adulthood. Experimental Aging Research, 34, 188-219. doi: 10.1080/03610730802070068

Borella, E., Carretti, B., Riboldi, F., \& De Beni, R. (2010). Working memory training in older adults: evidence of transfer and maintenance effects. Psychology and Aging, 25, 767-778. doi: 10.1037/ a0020683

Brehmer, Y., Li, S.-C., Müller, V., von Oertzen, T., \& Lindenberger, U. (2007). Memory plasticity across the life span: uncovering children's latent potential. Developmental Psychology, 43, 465-478. doi: 10.1037/0012-1649.43.2.465

Brehmer, Y., Westerberg, H., \& Bäckman, L. (2012). Working-memory training in younger and older adults: training gains, transfer, and maintenance. Frontiers in Human Neuroscience, 6, 63. doi: 10.3389/fnhum.2012.00063

Brzeziński, J. (2000). Badania eksperymentalne w psychologii $i$ pedagogice [Experimental research in psychology and pedagogics]. Warszawa: Wydawnictwo Naukowe Scholar.

Burgess, G. C., Gray, J. R., Conway, A. R., \& Braver, T. S. (2011). Neural mechanisms of interference control underlie the relationship between fluid intelligence and working memory span. Journal of Experimental Psychology General, 140, 674-692. doi: 10.1037/a0024695

Chooi, W.-T., \& Thompson, L. A. (2012). Working memory training does not improve intelligence in healthy young adults. Intelligence, 40, 531-542. doi: 10.1016/j.intell.2012.07.004

Colom, R., Román, F. J., Abad, F. J., Shih, P. C., Privado, J., Froufe, M., Escorial, S., Martínez, K., Burgaleta, M., Quiroga, M. A., Karama, S., Haier R. J., Thompson, P. M., \& Jaeggi, S. M. (2013). Adaptive n-back training does not improve fluid intelligence at the construct level: Gains on individual tests suggest that training may enhance visuospatial processing. Intelligence, 41, 712-727. doi: 10.1016/j.intell.2013.09.002

Colom, R., Rubio, V. J., Shih, P. C., \& Santacreu, J. (2006). Fluid intelligence, working memory and executive functioning. Psicothema, 18, 816-821.

Dahlin, E., Nyberg, L., Bäckman, L., \& Neely, A. S. (2008). Plasticity of executive functioning in young and older adults: immediate training gains, transfer, and long-term maintenance. Psychology and Aging, 23, 720-730. doi: 10.1037/a0014296

Dennis, N. A., \& Cabeza, R. (2008). Neuroimaging of healthy cognitive aging. In: F. I. M. Craik \& T. A. Salthouse (eds.), Handbook of aging and cognition. $\left(3^{\text {th }}\right.$ ed.) (pp. 1-54). Mahwah, NJ: Erlbaum.
Dorbath, L., Hasselhorn, M., \& Titz, C. (2011). Aging and executive functioning: A training study on focus-switching. Frontiers in Psychology, 2, 1-12. doi: $10.3389 /$ fpsyg.2011.00257

Engle, R. W. (2002). Working memory capacity as executive attention. Current Directions in Psychological Science, 11, 19. doi: 10.1111/1467-8721.00160

Engle, R. W., \& Kane, M. J. (2004). Executive attention, working memory capacity, and a two-factor theory of cognitive control. The Psychology of Learning and Motivation, 44, 145-199. doi: 10.1016/S00797421(03)44005-X

Feldman Barett, L., Tugade, M. M, \& Engle, R. W. (2004). Individual differences in working memory capacity and dual-process theories of the mind. Psychological Bulletin, 130, 553-573. doi: 10.1037/0033-2909.130.4.553

Fukuda, K., Vogel, E., Mayr, U., \& Awh, E. (2010). Quantity, not quality: the relationship between fluid intelligence and working memory capacity. Psychonomic Bulletin \& Review, 17, 673-679. doi: 10.3758/17.5.673

Gamrowska, A., \& Steuden, S. (2014). Coping with the events of daily life and quality of life of the socially active elderly. Health Psychology Report, 2, 123-131.

Garon N., Bryson S. E., \& Smith I. M. (2008). Executive function in preschoolers: a review using an integrative framework. Psychological Bulletin, 134, 31-60.

Gray, J. R., Chabris, C. F., \& Braver, T. S. (2003). Neural mechanisms of general fluid intelligence. $\mathrm{Na}$ ture Neuroscience, 6, 316-322. doi: 10.1038/nn1014

Hasher, L., \& Zacks, R. T. (1988). Working memory, comprehension, and aging: A review and a new view. In: H. Bower (ed.), The Psychology of Learning and Motivation (vol. 22) (pp. 193-225). San Diego, CA: Academic Press.

Hertzog, C., Kramer, A. F., Wilson, R. S., \& Lindenberger, U. (2009). Enrichment effects on adult cognitive development. Psychological Science, 9, 1-65. doi: 10.1111/j.1539-6053.2009.01034.x

Hofer, S. M. \& Alwin, D. F. (eds.). (2008). Handbook of Cognitive Aging. Interdisciplinary Perspectives. Thousand Oaks, CA: Sage Publications.

Jaeggi, S. M., \& Buschkuehl, M. (2014). Working memory training and transfer: theoretical and practical considerations. New Frontiers of Multidisciplinary Research in STEAM-H (Science, Technology, Engineering, Agriculture, Mathematics, and Health), 90, 19-44. doi: 10.1007/978-3-319-07755-0

Jaeggi, S. M., Buschkuehl, M., Jonides, J., \& Perrig, W. J. (2008). Improving fluid intelligence with training on working memory. Proceedings of the National Academy of Sciences of the United States of America, 105, 6829-6833. doi: 10.1073/pnas.0801268105

Jaeggi, S. M., Buschkuehl, M., Jonides, J., \& Shah, P. (2011). Short- and long-term benefits of cognitive training. Proceedings of the National Academy
Effects of training of basic cognitive functions in adult individuals 
of Sciences of the United States of America, 108, 10081-10086. doi: 10.1073/pnas. 1103228108

Jaeggi, S. M., Buschkuehl, M., Shah, P., \& Jonides, J. (2014). The role of individual differences in cognitive training and transfer. Memory \& Cognition, 42, 464-480. doi: 10.3758/s13421-013-0364-z

Jaušovec, N., \& Jaušovec, K. (2012). Working memory training: Improving intelligence - changing brain activity. Brain and Cognition, 79, 96-106. doi: 10.1016/j.bandc.2012.02.007

Ludmiła

Zając-Lamparska, Janusz Trempała

Jaworowska, A., \& Szustrowa, T. (2007). Test Matryc Ravena w wersji Standard TMS. Formy: Klasyczna, Równolegta, Plus [Raven's Standard Progressive Matrices Test. Versions: Classical, Parallel and Plus]. Warszawa: Pracownia Testów Psychologicznych.

Jodzio, K. (2008). Neuropsychologia intencjonalnego dziatania. Koncepcje funkcji wykonawczych [Neuropsychology of intentional action. Conceptions of executive functions]. Warszawa: Wydawnictwo Naukowe Scholar.

Kane, M. J., \& Engle, R. W. (2002). The role of prefrontal cortex in working-memory capacity, executive attention, and general fluid intelligence: An individual-differences perspective. Psychonomic Bulletin \& Review, 9, 637-671. doi: 10.3758/BF03196323

Karbach, J., \& Kray, J. (2009). How useful is executive control training? Age differences in near and far transfer of task-switching training. Developmental Science, 12, 978-990. doi: 10.1111/j.14677687.2009.00846.x

Karbach, J., \& Verhaeghen, P. (2014). Making working memory work: a meta-analysis of executive-control and working memory training in older adults. Psychological Science, 25, 2027-2037. doi: 10.1177/0956797614548725

Kroemeke, A., \& Gruszczyńska, E. (2014). Depressive symptom clusters among the elderly: a longitudinal study of course and its correlates. Health Psychology Report, 2, 269-279.

Li, S.-C., Schmiedek, F., Huxhold, O., Röcke, C., Smith, J., \& Lindenberger, U. (2008). Working memory plasticity in old age: practice gain, transfer, and maintenance. Psychology and Aging, 23, 731-742. doi: 10.1037/a0014343

Leszko, M., Zając-Lamparska, L., \& Trempała, J. (2015). Aging in Poland. The Gerontologist, 55, 707-715. doi: 10.1093/geront/gnu 171

Lustig, C., Shah, P., Seidler, R., \& Reuter-Lorenz, P. A. (2009). Aging, training, and the brain: a review and future directions. Neuropsychology Review, 19, 504-522. doi: 10.1007/s11065-009-9119-9

Melby-Lervåg, M., \& Hulme, C. (2013). Is working memory training effective? a meta-analytic review. Developmental Psychology, 49, 270-291. doi: 10.1037/a0028228

Miyake, A., Friedman, N. P., Emerson, M. J., Witzki, A. H., Howerter, A., \& Wager, T. D. (2000). The unity and diversity of executive functions and their contributions to complex "Frontal Lobe" tasks: a latent variable analysis. Cognitive Psychology, 41, 49-100. doi: 10.1006/cogp.1999.0734

Nęcka, E., Orzechowski, J., \& Szymura, B. (2006). Psychologia poznawcza [Cognitive psychology]. Warszawa: Wydawnictwo Naukowe PWN, ACADEMICA Wydawnictwo SWPS.

Oberauer, K., Süß, H. M., Wilhelm, O., \& Sander, N. (2007). Individual differences in working memory capacity and reasoning ability. In: A. R. A. Conway, C. Jarrold, M. J. Kane, A. Miyake, \& J. N. Towse (eds.), Variation in working memory (pp. 49-75). Oxford: Oxford University Press.

Redick, T. S., Shipstead, Z., Harrison, T. L., Hicks, K. L., Fried, D. E., Hambrick, D. Z., Kane, M. J., \& Engle, R. W. (2013). No evidence of intelligence improvement after working memory training: a randomized, placebo-controlled study. Journal of Experimental Psychology. General, 142, 359-379. doi: 10.1037/ a0029082

Salthouse, T. A. (2014). Relations between running memory and fluid intelligence. Intelligence, 43, 1-7. doi: 10.1016/j.intell.2013.12.002

Salthouse T. A. (1994). Age-related changes in basic cognitive processes. In: M. Storandt \& G. R. VandenBos (eds.), The Adult Years: Continuity and Change (pp. 5-40). Washington: American Psychological Association.

Sheppard, L. D., \& Vernon, P. A. (2008). Intelligence and speed of information-processing: A review of 50 years of research. Personality and Individual Differences, 44, 535-551.

Schmiedek, F., Bauer, C., Lövdén, M., Brose, A., \& Lindenberger, U. (2010). Cognitive enrichment in old age. GeroPsych: The Journal of Gerontopsychology and Geriatric Psychiatry, 23, 59-67. doi: 10.1024/1662-9647/a000013

Schubert, T., Strobach, T., \& Karbach, J. (2014). New directions in cognitive training: on methods, transfer, and application. Psychological Research, 78, 749-755. doi: 10.1007/s00426-014-0619-8

Shipstead, Z., Redick, T. S., \& Engle, R. W. (2012). Is working memory training effective? Psychological Bulletin, 138, 628-654. doi: 10.1037/a0027473

Sternberg, R. J. (2008). Increasing fluid intelligence is possible after all. Proceedings of the National Academy of Sciences of the United States of America, 105, 6791-6792. doi: 10.1073/pnas. 0803396105

Steine-Morrow, E. A. L., \& Basak, C. (2011). Cognitive interventions. In: K. W. Schaie \& S. L. Willis (eds.), Handbook of the Psychology of Aging ( $7^{\text {th }}$ ed.) (pp. 153-171). San Diego, CA: Academic Press.

Strenziok, M., Parasuraman, R., Clarke, E., Cisler, D. S., Thompson, J. C., \& Greenwood, P. M. (2014). Neurocognitive enhancement in older adults: comparison of three cognitive training tasks to test a hypothesis of training transfer in brain connec- 
tivity. Neurolmage, 85, 1027-1039. doi: 10.1016/j. neuroimage.2013.07.069

Süß, H. M., Oberauer, K., Wittman, W. W., Wilhelm, O., \& Schulze, R. (2002). Working memory capacity explains reasoning ability - And a little bit more. Intelligence, 30, 261-288.

Taatgen, N. A. (2013). The nature and transfer of cognitive skills. Psychological Review, 120, 439-471. doi: $10.1037 / \mathrm{a} 0033138$

Thompson, T. W., Waskom, M. L., Garel, K. L. A., Cardenas-Iniguez, C., Reynolds, G. O., Winter, R., Chang, P., Pollard, K., Lala, N., Alvarez, G. A., \& Gabrieli, J. D. E. (2013). failure of working memory training to enhance cognition or intelligence. PLoS One, 8, e63614. doi: 10.1371/journal.pone.0063614

Unsworth, N., \& Engle, R. W. (2007). The nature of individual differences in working memory capacity: active maintenance in primary memory and controlled search from secondary memory. Psychological Review, 114, 104-132. doi: 10.1037/0033295X.114.1.104

Unsworth, N., Fukuda, K., Awh, E., \& Vogel, E. K. (2014). Working memory and fluid intelligence: Capacity, attention control, and secondary memory retrieval. Cognitive Psychology, 71, 1-26. doi: 10.1016/j.cogpsych.2014.01.003

Unsworth, N., \& Spillers, G. J. (2010). Working memory capacity: Attention control, secondary memory, or both? A direct test of the dual-component model. Journal of Memory and Language, 62, 392406. doi: 10.1016/j.jml.2010.02.001

Unsworth, N., Spillers, G. J., Kane, M. J., Engle, R. W., \& Schmiedek, F. (2009). Examining the relations among working memory capacity, attention control, and fluid intelligence from a dual-component framework. Psychology Science Quarterly, 9, 637-671.

Verhaeghen, P., Cerella, J., Bopp, K. L., \& Basak, C. (2006). Starzenie się i różne rodzaje kontroli poznawczej: przegląd metaanaliz odporności na interferencję, koordynacji i przełączania się między zadaniami oraz eksperymentalne poszukiwania nad związaną z wiekiem wrażliwością w niedawno zidentyfikowanym procesie przerzucania uwagi [Ageing and different types of cognitive control: a review of meta-analyses of resistance to interference, coordination and switching between tasks, as well as experimental research of susceptibility associated with age in the recently identified process of attention switching]. In: R. W. Engle, G. Sędek, U. von Hacker, \& D. N. McInstosh (eds.), Ograniczenia poznawcze. Starzenie się i psychopatologia (pp. 172-206). Warszawa: Wydawnictwo Naukowe PWN.

Von Bastian, C. C., Langer, N., Jäncke, L., \& Oberauer, K. (2013). Effects of working memory training in young and old adults. Memory \& Cognition, 41, 611-624. doi: 10.3758/s13421-012-0280-7

Von Bastian, C. C., \& Oberauer, K. (2014). Effects and mechanisms of working memory training: a review. Psychological Research, 78, 803-820. doi: 10.1007/s00426-013-0524-6

Zając-Lamparska, L., Trempała, J., \& Mrówka, A. (2013). Stereotypes inhibition in syllogistic reasoning changes related to age and time measurement repetition during study. Polskie Forum Psychologiczne, 18, 469-485.

Zinke, K., Zeintl, M., Rose, N. S., Putzmann, J., Pydde, A., \& Kliegel, M. (2014). Working memory training and transfer in older adults: effects of age, baseline performance, and training gains. Developmental Psychology, 50, 304-315. doi: 10.1037/a0032982
Effects of training of basic cognitive functions in adult individuals 